\title{
Notes on the Review and Publication Process
}

Though this is the first issue of Human Development under our tenure, Melanie Killen (Associate Editor) and I have been at work at our editorial desks for over a year now. Let me share some of our behind-the-scenes activities that will lead to the work we will publish in forthcoming issues.

One of our activities is coordinating manuscript review. This is a standard process for most journal editors, though Human Development diverges from the typical in some key ways. Upon receiving a manuscript, we engage in a first read to determine whether the submission is at least loosely aligned with the broad purposes of the journal. We favor manuscripts that are conceptual in nature, in which authors draw on empirical findings and observations to raise theoretical issues, flesh out potentially powerful ideas, and differentiate key constructs. This conceptual orientation of the journal is critical to a field of study that is inherently interdisciplinary, one in which questions of 'what to study?' and 'how to study it?' differ widely by theoretical, disciplinary, and methodological commitments.

Once we decide that a manuscript fits or is close to fitting these criteria, we send the manuscript to scholars who have relevant expertise. These reviewers may be members of our newly constituted Editorial Board (see the masthead) or scholars whose views are critical to evaluation of the submission. We have been gratified by the willingness of the academic community to contribute careful and insightful reviews. With reviews in hand, we reconsider the manuscript. As one might imagine in a cross-disciplinary area of study that is ripe with controversy, our reviewers are often not of uniform opinion in their assessment of the scholarly merit of a manuscript. In these situations, we evaluate the manuscript in relation to the reviews, the value of the manuscript to the journal's readership, and our own appraisals of the author's contribution, favoring those articles that offer new insights and build upon or take issue with prior scholarship. The review process is more than a gatekeeper. More often than not, it contributes to the refinement of an article, encouraging greater clarity of exposition and sometimes even the modification and elaboration of important conceptual contributions.

Human Development includes more than the publication of unsolicited manuscripts. Melanie and I are continuing the journal's policy to publish commentaries on accepted papers as well as reviews of important books. These contributions originate as invitations to researchers with known expertise in a targeted area of

\begin{tabular}{ll}
\hline KARGER & $\begin{array}{l}\text { (2003 S. Karger AG, Basel } \\
\text { 0018-716X/03/0461-0001\$19.50/0 }\end{array}$ \\
Fax +4161306 1234 & \\
$\begin{array}{l}\text { E-Mail karger@karger.ch } \\
\text { www.karger.com }\end{array}$ & $\begin{array}{l}\text { Accessible online at: } \\
\text { www.karger.com/hde }\end{array}$
\end{tabular}


inquiry. Commentaries are designed to set a lead paper in some scholarly context by including another scholar's view of the paper's significance, its potential for future influence, or alternative perspectives. Essay reviews are thoughtful analyses of an important book by a scholar active in the related field. Reviewers often use the book as a context to further a discussion of current ideas and controversies, and thus readers gain insight into why this field is of interest, what the book adds to it, or what new questions it raises. Our role is to review both commentaries and reviews for clarity. Like the published papers, commentaries and reviews are guided through a series of revisions prior to publication.

Our endeavors to date have been rewarding. We are impressed by the range of cross-disciplinary submissions that converge on analyses of developmental phenomena. In forthcoming issues, you will find conceptual and empirical discussions of developmental issues related to comparative psychology, evolutionary treatments of development, anthropology, and linguistics, among others.

The work of the journal is a distributed endeavor, depending upon both the contributions of the research community and Karger, the journal's publishers. Melanie and I are grateful for the opportunity to contribute and work with others, and we expect to provide the journal's readership scholarly and thought-provoking contributions in the coming years.

G.B. Saxe, Editor, Berkeley, CA 